Research Journal of Applied Sciences, Engineering and Technology 6(14): 2621-2624, 2013

DOI:10.19026/rjaset.6.3748

ISSN: 2040-7459; e-ISSN: 2040-7467

(C) 2013 Maxwell Scientific Publication Corp.

Submitted: January 05, $2013 \quad$ Accepted: February 08, 2013

Published: August 10, 2013

\title{
Research Article \\ Effect of Low Temperature Heat Treatment on Different Original Graphite Microstructures of Nodular Cast Iron
}

\author{
Yan Zhao \\ Department of Mechanical and Electronical Engineering, Dezhou University, Dezhou 253023, China \\ Research Institute of Engineering Materials, Dezhou University, Dezhou 253023, China
}

\begin{abstract}
To understand the effect of low temperature heat treatment on microstructure of nodular graphite, nodular cast irons with the same chemical composition but different microstructure were made by the heredity of raw materials. The effects of low temperature heat treatment on the different microstructures of graphite were studied. The results show that after the low temperature treatment, the modularization rate and level are improved observably for as-cast graphite with lower degree of graphitization and worse effect of nodularization and the mean sphere diameter of the graphite increases; the spot graphite arises for as-cast graphite with higher degree of graphitization and better effect of nodularization, the mean sphere diameter of the graphite decreases, the spot and nodular graphite distribute alternately, the spheroidization grade and nodularization rate do not change obviously.
\end{abstract}

Keywords: Low temperature heat treatment, microstructure of graphite, nodular graphite cast iron

\section{INTRODUCTION}

With the advent of nodular graphite cast iron since 1940 s, it has been widely used in mechanical engineering and other fields due to its predominant performance and lower production cost. Along with the rapid development of mechanical industry, the higher performance of nodular graphite cast irons has been put forward. In order to improve the microstructure and performance of nodular graphite cast iron further, scientific researchers have not only been limited to the research areas of casting process and material optimization, but also the effect of heat treatment, especially the low temperature heat treatment has attached a lot of academic attention increasingly by virtue of its low energy consumption and low cost (Hao, 2004).

The principal factors those affect the microstructure and performance of nodular graphite cast iron are microstructure of matrix, graphite's shape, size, quantity, distribution and so on (Gülcan et al., 2006; Zhao et al., 2004; Torsten and Ingvar, 2007; Nuno et al., 2008; Hao and Yang, 2008). At present, researches about the effect of heat treatment on matrix of nodular graphite cast iron are comparative maturity (Chang et al., 2006, 2008; Martínez-Madrid et al., 2002; Putatunda and Gadicherla, 2000; Delia et al., 1998), but the reports about the effect of heat treatment on microstructure of graphite are less.

In order to get a comprehensive understanding of the effect of low temperature heat treatment on microstructure of nodular graphite, at the same time considering reducing the energy consumption and production cost. The effects of low temperature heat treatment on different original graphite structures of nodular graphite cast irons are studied in this study.

\section{METHODOLOGY}

Five samples of nodular graphite cast iron with the same chemical composition used for heat treatment in this study were made by the heredity of raw materials in our previous work (Zhao and Yang, 2009). The main chemical compositions of raw materials for nodular graphite cast irons production are listed in Table 1. Schemes of mixture ratio are shown in Table 2. Under the techniques of carbureting and silicon content regulating, samples were casting into sand molds with a size of $\Phi 40 \times 150 \mathrm{~mm}$. The finally chemical composition of nodular graphite cast irons is controlled as: C3.62$3.64 \%$, Si 2.52-2.55\%, Mn 0.23-0.50\%, S $\leq 0.015 \%$, $\mathrm{P} \leq 0.05 \%$ (Xie and Yang, 2007). The low temperature heat treatment process of samples is holding at $700^{\circ} \mathrm{C}$ for $2 \mathrm{~h}$, then taken out air cooling. The microstructures of samples were observed by the optical microscope and high power video microscope HK-2200. The changes of samples' graphite microstructures after low temperature heat treatment were analyzed comparing with their original microstructures.

\section{RESULTS AND DISCUSSION}

Figure 1 shows as-cast graphite forms of each nodular graphite cast iron. As can be seen from Fig. 1 that the nodular graphite cast irons with the same chemical composition but different schemes of mixture 
Res. J. Appl. Sci. Eng. Technol., 6(14): 2621-2624, 2013

Table 1: Chemical composition of raw materials (mass fraction, \%)

\begin{tabular}{lllllllll}
\hline Composition & $\mathrm{C}$ & $\mathrm{Si}$ & $\mathrm{Mn}$ & $\mathrm{S}$ & $\mathrm{P}$ & $\mathrm{Mg}$ & $\mathrm{RE}$ & $\mathrm{Ca}$ \\
\hline Q12 pig iron & 4.40 & 1.100 & 0.15 & 0.020 & 0.050 & - & - & - \\
Scrap steel & 0.52 & 0.315 & 0.55 & 0.024 & 0.021 & - & - \\
Nodularizer & - & 41.000 & - & - & - & 8.0 & 4.5 & 2.6 \\
\hline
\end{tabular}

Table 2: Different mixture ratio of pig iron and scrap steel (mass

\begin{tabular}{|c|c|c|c|c|c|}
\hline Samples & $1^{\#}$ & $2^{\#}$ & $3^{\#}$ & $4^{\#}$ & $5^{\#}$ \\
\hline Pig iron: scrap steel & $4: 1$ & $3: 2$ & $2: 3$ & $1: 4$ & $0: 5$ \\
\hline
\end{tabular}
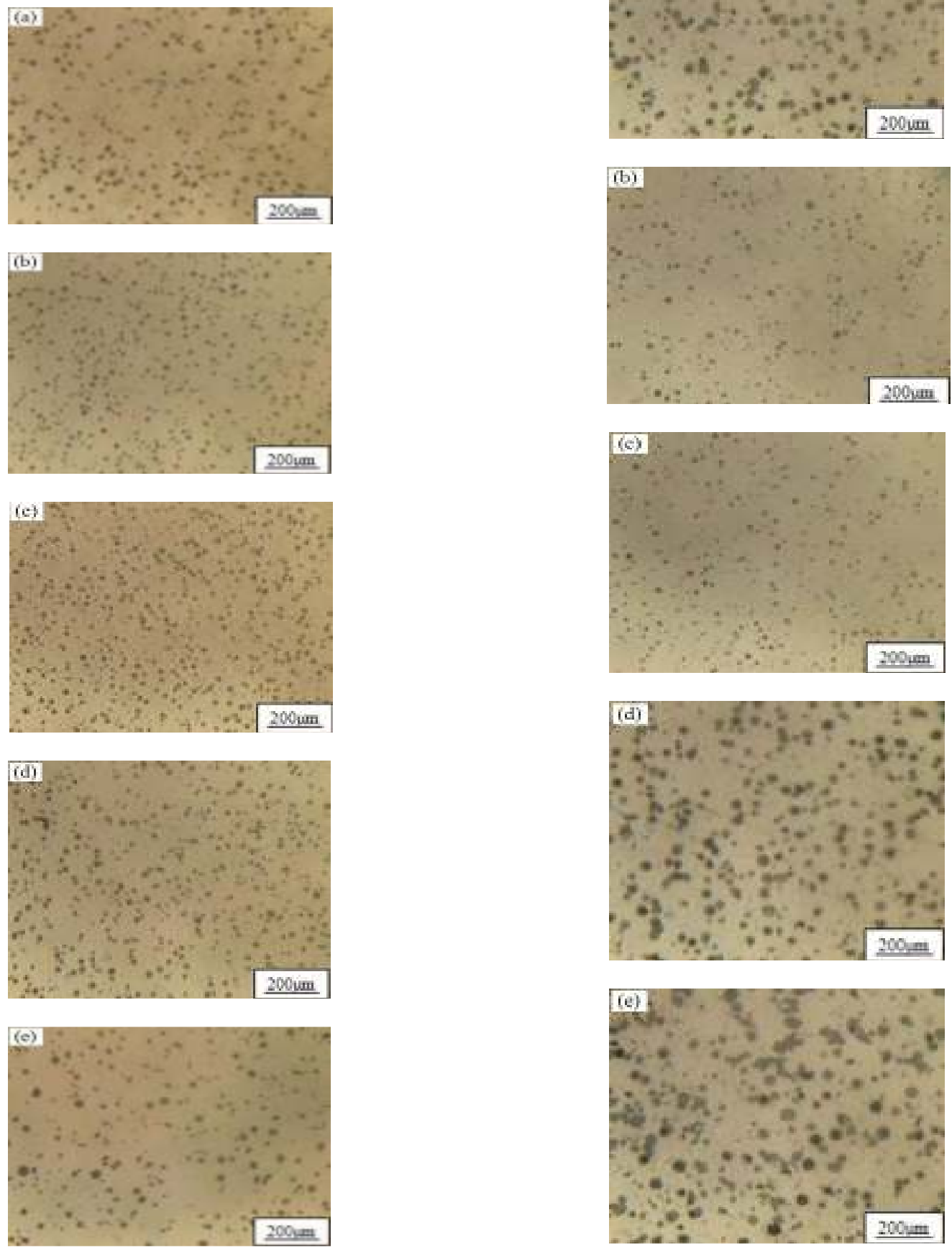

Fig. 1: As-cast graphite microstructures of nodular graphite cast irons made by different mixture ratio (a) $1^{\#}$ sample, (b) $2^{\#}$ sample, (c) $3^{\#}$ sample, (d) $4^{\#}$ sample, (e) $5^{\#}$ sample

Fig. 2: As low temperature heat-treated graphite microstructures of nodular graphite cast irons made by different mixture ratio (a) $1^{\#}$ sample, (b) $2^{\#}$ sample, (c) $3^{\#}$ sample, (d) $4^{\#}$ sample, (e) $5^{\#}$ sample 
ratio have different texture characteristics due to the heredity of raw materials.

The graphitization degree and nodularization effect are not too well for sample $1^{\#}$ and $4^{\#}$. The proportion of graphite is less with a $3^{\text {rd }}$ spheroidization grade, a $80 \%$ nodularization rate and a 4.5 grade of graphite size. Sample $2^{\#}$ and $3^{\#}$ are less affected by the heredity of raw materials, so the graphitization degree and nodularization effect are improved obviously. The graphite are numerous and fine with a $1^{\text {st }}-2^{\text {nd }}$ spheroidization grade, a $90-95 \%$ nodularization rate and a 5.5 grade of graphite size. Sample $5^{\#}$ is affected the most by the heredity of raw materials, the graphite are few and far between and present spherical and vermiform with a $5^{\text {th }}$ spheroidization grade, a $65 \%$ nodularization rate and a 4 grade of graphite size.

Figure 2 shows graphite microstructures of each nodular graphite cast iron after the low temperature heat treatment. As can be seen from Fig. 2 that the different original graphite microstructures of nodular graphite cast irons are affected diversely by the low temperature heat treatment. The nodularization effects (spheroidization grade and nodularization rate) of $1^{\#}, 4^{\#}$ and $5^{\#}$ are improved obviously. Especially for sample $5^{\#}$, the vermicular graphite trends to nodulizing. But the graphite of the three samples grows up obviously comparing with its original graphite microstructure before the low temperature heat treatment. For samples $2^{\#}$ and $3^{\#}$, there appear some spot graphite after the low temperature heat treatment. And the average sphere diameters of the graphite nodules decrease, but the spheroidization grade and nodularization rate have no obvious change.

The main reason for the above phenomenon is the diffusion behavior of carbon atom in the low temperature heat treatment process. One aspect is that carbon atoms of the graphite nodule diffuse from the outer surface of the graphite nodule to the matrix gradually. On the other hand, carbon atoms dissolved in the matrix diffuse from the matrix to the interfacial zone of the graphite nodule and matrix and then accumulate on the surface of the graphite nodule (Yao et al., 2000).

As a result of the low heat treatment temperature used in this study, eutectoid cementite in pearlite is difficult to decompose and separate out graphite, which can be found out from Fig. 3 (the matrix structure after heat treatment) that the percentage of pearlite is almost unchanged compared with the matrix structure before heat treatment (Zhao and Yang, 2009).

Furthermore, it is impossible that carbon atoms diffuse from the matrix to the interfacial zone of the graphite nodule and matrix. So, the changes of the graphite nodule mainly depend on carbon atoms' diffusing from the outer surface of the graphite nodule to the matrix and the concentration gradient of atoms is the driving force for the diffusing of carbon atoms. Because the graphitization degree and nodularization effect of samples $1^{\#}, 4^{\#}$ and $5^{\#}$ before the low temperature heat treatment are not satisfied, as shown
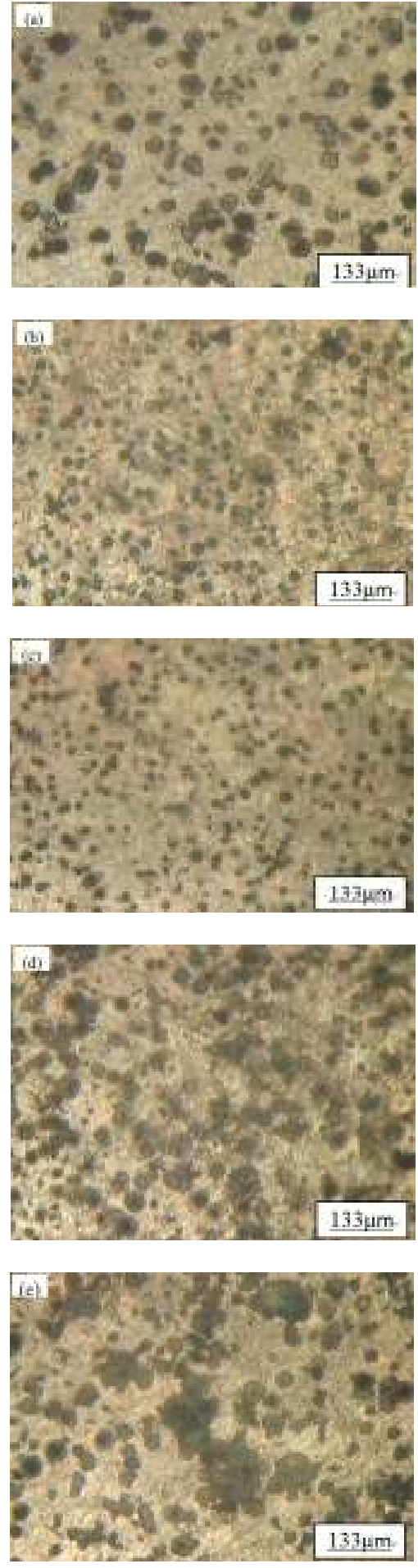

Fig. 3: As low temperature heat-treated matrix structures of nodular graphite cast irons made by different mixture ratio (a) $1^{\#}$ sample, (b) $2^{\#}$ sample, (c) $3^{\#}$ sample, (d) $4^{\#}$ sample, (e) $5^{\#}$ sample

in Fig. 1a to e, therefore, the carbon atom content in the matrix is relatively high. The less concentration gradient of carbon atom between the matrix and graphite nodule results in a slow diffusing from the 
outer surface of the graphite nodule to the matrix. Especially, the cooling rate is comparatively fast when the air cooling is used, most of the carbon atoms cannot diffuse to the matrix far away from the graphite nodule and form a carbon-rich zone near the original graphite, which results in the sphere diameter of the graphite increasing. Simultaneously, to reduce the surface free energy in the diffusing process of carbon atoms, the base level outward spherical crystal comes into being. Therefore, the nodularization effects are improved obviously comparing with those before heat treatment.

Roundness of the nodular graphite is improved, lumpish graphite transform into sphere, vermicular graphite trends to nodulizing, as shown in Fig. 2a, d and e. The spheroidization grade and nodularization rate of sample $2^{\#}$ and $3^{\#}$ are very good before the heat treatment. The graphite nodules are numerous and fine, therefore, the carbon atom content in the matrix is very low, which results in a comparatively large concentration gradient of carbon atom between the matrix and graphite nodule. This makes a portion of carbon atoms potentially get away from the graphite nodule and diffuse far away from the graphite to the matrix. When abundant carbon atoms of some graphite nodules diffused to the matrix, the carbon atom concentration gradient of the nearby matrix reduces certainly and prevents other surface carbon atoms of graphite nodules from diffusing. As a result of the fast diffusing of carbon atoms, the spot graphite partially arises from sample $2^{\#}$ and $3^{\#}$ after the low temperature heat treatment. On the whole, the mean sphere diameter of the graphite decreases, the spot and nodular graphite distribute alternately. At the same time, to get the lower surface free energy, the graphite still keeps spherical after the atomic diffusing process. Therefore, the spheroidization grade and efficiency do not change obviously before and after the low temperature heat treatment.

\section{CONCLUSION}

- The effects of low temperature heat treatment on the different original graphite microstructures of nodular graphite cast irons are diverse.

- For as-cast graphite with lower degree of graphitization and worse effect of nodularization, the nodularization rate and spheroidization grade are improved observably after the low temperature treatment. Lumpish graphite transforms into sphere, vermicular graphite trends to nodulizing, but the mean sphere diameter of the graphite increases.

- For as-cast graphite with higher degree of graphitization and better effect of nodularization, the spheroidization grade and nodularization rate do not change obviously after the low temperature treatment. But the spot graphite arises, the mean sphere diameter of the graphite decreases and the spot and nodular graphite distribute alternately.

\section{ACKNOWLEDGMENT}

The authors would like to thank science and technology program of Shandong province (Grant No. 2011YD03099).

\section{REFERENCES}

Chang, L.C., Z.C. Hsui and L.H. Chen, 2006. Effects of heat treatment on the erosion behavior of austempered ductile irons. Wear, 260: 783-793.

Chang, L.C., Z.C. Hsui and L.H. Chen, 2008. Influence of austenization temperature on the erosion behavior of austempered ductile irons. J. Univ., Sci. Technol. Beijing, 15(1): 29-31.

Delia, M., M. Alaalam and M. Grech, 1998. Effect of austenitizing conditions on the impact properties of an alloyed austempered ductile iron of initially ferritic matrix structure. JMEPEG, 7: 265-272.

Gülcan, T., T. Mustafa and T. Alaaddin, 2006. Effect of matrix structure on the impact properties of an alloyed ductile iron. Mater. Charact., 57: 290-299.

Hao, S.J., 2004. Modern Cast Iron. Metallurgical Industry Press, Beijing.

Hao, B.H. and M. Yang, 2008. Research on the relationship between shape and intensity of graphite ball. J. Beijing Inst. Petro-Chem. Technol., 16(1): 39-43.

Martínez-Madrid, M., M.A. Acosta and A. TorresAcosta, 2002. Effects of austempering temperature on fatigue crack rate propagation in a series of modified $(\mathrm{Cu}, \mathrm{Ni}$ and/or $\mathrm{Mo})$ nodular irons. JMEPEG, 11: 651-658.

Nuno, C., N. Machado and F.S. Silva, 2008. Influence of graphite nodules geometrical features on fatigue life of high-strength nodular cast iron. JMEPEG, 17: 352-362.

Putatunda, S.K. and P.K. Gadicherla, 2000. Effect of austempering time on mechanical properties of a low manganese austempered ductile iron. JMEPEG, 9: 193-203.

Torsten, S.G. and L.S. Ingvar, 2007. The Effect of graphite fraction and morphology on the plastic deformation behavior of cast irons. Metall. Mater. Trans. A, 38: 840-847.

Xie, R.C. and H. Yang, 2007. Effect of K/NA-RE Multiple modificator on nodular Iron produced by recaburation process. Hot Working Technol., 36(9): 425-427.

Yao, X.Q., X.F. Shu and Z.B. Xing, 2000. Study on growth mechanism of spherical graphite. J. Kunming Univ., Sci. Technol., 25(5): 56-59.

Zhao, Y. and H. Yang, 2009. Effect of raw material heredity on microstructure of nodular graphite cast iron. Foundry, 58(5): 502-504.

Zhao, X., T.F. Jing and Y.W. Gao, 2004. Morphology of graphite in hot-compressed nodular iron. J. Mater. Sci., 39: 6093-6096. 